\title{
Grounding Knowledge and Normative Valuation in Agent-Based Action and Scientific Commitment
}

\author{
Catherine Kendig
}

\section{Introduction}

If the goal of scientists is the acquisition of knowledge, then knowledge in general and scientific explanation in particular can surely be understood to be the product of that pursuit articulated as a unified set of observation statements. However, those focusing on scientific practice, disagree. They claim that knowledge is always understood with reference to a particular context and in light of the actions of an epistemic agent. Knowledge-making activities are not the result of universal rules for deriving explanation from facts but the result of critical intersubjective modes of investigation. A science-in-practice approach turns our attention to the activities of and communication between scientists in order to understand and characterize the nature of scientific inquiry. As such, it is part of what has been referred to as the practice turn. ${ }^{1}$ This refocusing of science on scientific practices highlights the activities that are revealed when we look at the processes and doings of science by scientists and scientific communities (e.g. hypothesizing, testing, experimenting, theorizing, measuring) rather than exclusively on the products of science (e.g. knowledge, equations, devices, theories). The practice turn in philosophy of science is not an apologetic for an andpractice-too approach to the metaphysics of science. A focus on practice provides a route to understanding the nature of the world in ways that have been, until recently, marginalized by aggressive demarcationist interests within traditional philosophy of science. This form of aggressive demarcationism held that research seeking to investigate scientific activity and the work of scientists was not really philosophy but just

\footnotetext{
${ }^{1}$ For research within the philosophy of science in practice and sociology of science in practice, see for instance the work of Hacking (1992, 1995), Dupré (1993), Chang (2004), Rouse (1996, 2003), Rheinberger (2005), De Regt et al. (2009), Soler (2012), Soler et al. (2014), and Kendig (2016b, c).

C. Kendig $(\bowtie)$

Department of Philosophy, Michigan State University,

503 South Kedzie Hall, 368 Farm Lane, East Lansing 48824-1032, MI, USA

e-mail: kendig@msu.edu
} 
sociology. ${ }^{2}$ Within philosophy, there was no worse criticism than the suggestion that what one's putatively philosophical research was up to was not philosophy but was instead sociology. For many in philosophy, the criticism amounted to disciplinary slur, and one to be avoided. This active avoidance by philosophers of science to engage with sociology of science meant that rather than crossing the divides between philosophy and sociology, many were instead burning any bridges that remained between them in an effort to protect the discipline from invasion.

Rather than seeking a purely theoretic approach to knowledge or wholly analytic approach to explanation, a philosophy of science in practice approach focuses on the activities required in theory-making, knowledge-making, and explaining. Why is this important? Focusing on an activity-based analysis allows us to "go beyond thinking about scientific explanation in terms of logical relations between explanandum and explanans, [and] we can consider how the act of explaining arises and how it is best performed" (Chang 2011: 208). So called pure theoretic approaches that omit reference to practice succeed in doing so only by assuming science and knowledge acquisition to be a subjectless state of affairs-activities with no actors, understanding with no one who understands, and modelling with no modellers. Chang suggests the solution to this problem is for us to go against the convention of avoiding the second person familiar "you" in our discourse, explanations, and discussions (Chang 2011). We should (as philosophers, sociologists, and scientists) recover the importance of what knowledge is as something you or I understand or explain, rather than as disembodied subjectless answers to questions (Chang 2011, 2016).

Implementing a science-in-practice approach, my aim is to turn attention to the work of practitioners reengineering metabolic pathways within chassis organisms such as E. coli. I ask, what, if anything, doing so can tell us about the relationship between the metaphysical, epistemological and ethical knowledge-making activities. As such it constitutes an activity-based analysis of scientific explaining and normative ethical thinking. If successful, it would suggest that an examination into the practice of science may also provide answers, (or at least more informed lines of questioning), for other long-discussed problems in philosophy.

I begin with a brief metaphysics and epistemology of classification. Disciplines have a system of classification that specifies the kinds of things that are the subject of study for that discipline, e.g. the periodic table of elements, plate tectonics, the DSM (Dupré 2006). Synthetic biology is no different. To understand the classification system one must focus on the processes by which it is used and made. Our behaviour is informed by what kinds of things we (presuppose) we are interacting with as well as the goals and values we rely upon in our investigation. In the first half of the chapter, I examine the nature of scientific inquiry and how the manipula-

${ }^{2}$ Chang has also pointed out the tendency of traditional philosophers of science as well as analytic philosophy in general to use the "just sociology" claim as criticism of practice based approaches to philosophy: "In the typical analytic philosopher's picture, the scientist only enters as a ghostly being that either believes or doesn't believe certain descriptive statements, fixing his beliefs following some rules of rational thinking that remove any need for real judgment. All the things that do not fit easily into this bizarre and impoverished picture are denigrated as pieces of "mere" psychology or sociology" (Chang 2014: 70). 
tion and use of different techniques within synthetic biology has metaphysical implications for the notion of parts and wholes, modularity, biological organization and function. The second half explores the social aspect of scientific inquiry in an attempt to reveal how normative valuations and ethical judgements are formed within and across synthetic biology communities. It concludes with a suggestion for how the epistemological, metaphysical, and ethical modes of inquiry are connected in networks of practitioners working together as moral agents - and that kinds of moral objects, epistemic objects, and metaphysical objects are made kinds through the activities of practitioners within these networks.

\section{Categories of Epistemological Activity in Synthetic Biology}

Early conceptual work in synthetic biology identified three different knowledgemaking distinctions that exist within the field (see O'Malley et al. 2008; O'Malley 2009; Morange 2009a). These were intended to distinguish three overlapping epistemological categories. The categories demarcate diverse knowledge-making distinctions that lead to different questions being asked, different methods used, different knowledge acquired through these, and different products or outcomes (O'Malley et al. 2008). The first of these three categories is whole genome engineering. In this, biological processes and modules are co-opted and redesigned to solve technological problems for the production of energy or chemicals required for various industries. The most publicized example of this was the synthesis of the first self-replicating, synthetic bacterial cell. This was achieved by Craig Venter and his company, Synthetic Genomics, who synthesized an entire bacterial genome and used it to replace the genome of Mycoplasma mycoides thereby creating JCVIsyn1.0 (Gibson et al. 2010; Hylton 2012). The second is the engineered construction of functional parts, processes, pathways, devices, and systems (Brent 2004; Endy 2005). The current attempts to modify metabolic pathways in bacteria, yeast, and algae to generate biofuels are examples of this (Dellomonaco et al. 2010; Georgianna and Mayfield 2012; Wang et al. 2013). This involves the design and testing of biological systems and their component parts. Understanding of these functional systems is born out in their decomposition, manipulation, and co-option. Understanding of these parts and networks is based on the structure and syntax of the system. Describing the syntactic structure of the biological network using engineering, logic, or mathematical models, researchers can gain knowledge of the behaviour of the module or pathway in terms of its input and output conditions. The third category of investigation is synthetic experimental evolution or protocell creation (Erwin and Davidson 2009; Morange 2009a). In this endeavour, synthetic biology seeks to understand the process of evolution, biological organization, and the nature of modularity. Understanding the process also opens up the potential to optimize the modules, networks, and systems which direct it.

This initial tripartite classification of synthetic biology provided important knowledge-making distinctions in the modes of research and knowledge based on 
these but it also led to further metaphysical questions. For instance, what kinds are the parts and processes to which these categories refer? And, what kinds of things are the parts, modules, and systems used within the discipline of synthetic biology? Pablo Schyfter $^{3}$ (2012) suggests what he calls an initial "exploration into things and kinds" offering a "first look analysis" of kindhood for the products of synthetic biology and suggests that they fit imperfectly within both technological kinds and natural biological kinds. He is critical of synthetic biologists for not considering kindhood and for using engineering as the model and exemplar on which to base synthetic biology.

Determining what kinds (i.e technological kinds or natural biological kinds or something else) exist in synthetic biology may ultimately rest on how the discipline itself and how it is understood in relation to other biological and engineering disciplines. The discipline of synthetic biology is sometimes conceived of by practitioners and detractors as a subset of functional biology and as such is characterized as an application-based, or technology-based mode of understanding that seeks to explain how something works (see Schyfter 2012 for problems with this view). It has also been characterized as evolutionary biology due to its attempt (especially in protocell creation) to answer why-questions: seeking why (rather than how) biological pathways, devices, and parts work. This difference in the attribution of goals, products, and techniques depending on what types of questions are being asked make the categorization of synthetic biology as a hybrid or disunified discipline unsurprising. Its growing epistemic and methodological toolkit seems likely to continue apace-the result of sourcing and modifying techniques from biology, chemistry, computer science, mathematics, and engineering (see Morange 2009b; Keller 2009; O'Malley et al. 2008 for discussions of the discipline-building of synthetic biology).

But relying on this dichotomy of functional and evolutionary biology, of howand why-questions does not seem entirely justified — or at least is not always elucidatory-within synthetic biology. Knowledge-seeking questions within synthetic biology do not focus purely on how-questions directed for the purpose of modifying function. I suggest elsewhere (Kendig 2016a, b) that such dichotomizations fail to identify the union of how- and why-questions, their mode of investigation, and categorization and kind-making (or what I've called "kinding") practices typified by synthetic biology. The making or constructing of material objects, mechanisms, processes, or pathways; the theoretical construction of models and algorithms; as well as the devising of repeatable methods and techniques being made in synthetic biology are all instances of kinding - where kinding is understood as the epistemological and ontological activities within the practice of synthetic biology and by which the categories of that discipline or subdiscipline are configured. The outputs of these practices - the products of diverse synthetic biological research aims, are exchangeable and repeatable activities that represent, explain, and further advance

\footnotetext{
${ }^{3}$ Schyfter (2012) considers and evaluates the appropriateness of conceiving the products of synthetic biological research as kinds of technological objects. The discussion here differs from his insofar as I take a practice-based account of kinds that focuses on kinds of modules (see also Sprinzak and Elowitz 2005; Keller 2009).
} 
our understanding of the relation of parts and wholes, the manipulation of developmental pathways, and the nature of biological functioning and organization. This is exemplified in the engineered construction of functional parts, processes, pathways, devices, and systems (Brent 2004; Endy 2005). For example, the current attempts to modify metabolic pathways in bacteria, yeast, and algae to generate biofuels (Dellomonaco et al. 2010; Georgianna and Mayfield 2012; Wang et al. 2013) rely on the modification of metabolic pathways through design and testing of biological systems and their component parts.

Understanding of these functional systems is born out in their decomposition, manipulation, and co-option. The type of synthetic biology focused on the engineered construction of functional parts, processes, pathways, devices, and systems is in the business of producing standardized parts, devices, pathways and modules with known functions. Standard biological parts with known functions are catalogued in a number of registries (e.g. Massachusetts Institute of Technology Registry of Standard Biological Parts). Insofar as these parts are kinds, this practice is the making of these parts.

In response to Schyfter (2012), I suggest that the imperfect fit of the parts and processes of synthetic biology into technological or biological kinds is because that which is kinded is epistemologically heterogeneous. If synthetic biology provides knowledge of how systems work, then the explanations of nature it provides (e.g. about how to re-engineer and manipulate them) suggest that it may be more profitably conceived of as a discipline that is epistemologically, ontologically, and methodologically hybrid. In the next section, I characterize the practice of part-making in metabolic engineering. I suggest that this practice can be couched in terms of different kinds of modularizing. It can be understood as a study of kinds of synthetic biological objects in the making and the nature of those things that make up the discipline (and subdisciplines) of synthetic biology.

\section{The Tangle of Modularity}

The activities of practitioners whose work focuses on the engineered construction of functional parts, processes, pathways, devices, and systems appear to be at least in part based on an underlying philosophical premise - that the world is organized in a certain way - that living organisms have an organization that is modular and that the variation that natural selection acts upon results from the recombining of modules. The premise of biological modularity is an ontological claim that appears to come out of this particular form of synthetic biological practice. We understand that the biological world is modular because we can manipulate different parts of organisms in ways that would only work if there were discrete parts that were interchangeable. This is the foundation of the BioBrick assembly method widely used in synthetic biology (Knight 2003). It is one of a number of methods that allows practitioners to construct and reconstruct biological pathways and devices using DNA libraries of standardized parts with known functions. 
Because of its pick-and-mix approach to disciplinary tool sourcing, synthetic biology may be particularly well-suited to unpick the tangled meanings of concepts that have been long-debated within evolutionary and functional biology (Morange 2009a: 374). Modularity, constraints, and convergence can be stripped down and analysed and given functional parts-language descriptions through synthetic biological experimentation and manipulation of genomes of model organisms, such as that of the synthetic biology workhorse, E. coli. In the following, I explore how metabolic engineering, as an epistemic tool, may be used to disentangle the multiple notions of two of these concepts-modularity and fitness.

Modularity has been a concept much discussed (Schlosser and Wagner 2004; Wagner et al. 2007). Although seen to be a central principle of functional biology in general and synthetic biology in particular, it continues to cause confusion. Within the emerging discipline of synthetic biology, this inbuilt ambiguity means that context is usually required for the use of the term to confer knowledge about the system from one practitioner to another.

"Modularity" is used to identify at least two different kinds of claims within synthetic biology. I refer to these different forms following the philosophical convention for discriminating broad claims from specific claims of concepts using uppercase and lowercase letters: Modularity and modularity. ${ }^{4}$

1. Modularity. A general thesis about the nature of all biological organization as being made up of relatively independent components, like building blocks. This can be a metaphysical claim: that the organization of living things is Modular; a claim that applies with univocality to all biological structures. It can be a methodological claim; that the best way to proceed with research is to look for Modularity. It can be an epistemic claim, that the world is knowable and we gain understanding by considering it is Modularly organized. ${ }^{5}$

2. modularity. A specific claim about the parthood of a particular organism, pathway, device, or process. This conception focuses on the property of being a part and the metaphysical relationship of individuation or composition of it as it relates to a whole. The claim of modularity is one about the nature of parts and wholes. Included under this kind of claim are various sub-characterizations, for instance: that parts are relatively autonomous, interchangeable, or independent of the context of other parts, carry out measurable functions, standardisable, or are non-decomposable.

These two forms frame different spaces of epistemological and ontological investigation. In doing so, they configure the level of biological organization to which the

\footnotetext{
${ }^{4}$ When referring simultaneously to "Modularity" and "modularity" I will use the admittedly awkward "M/modularity".

${ }^{5}$ Each of these claims can be either conceived of from a realist, antirealist, operationalist, or pragmatic view as well as either one of monism or pluralism. For instance, one might suggest Modularity is a pragmatic methodology (and that we can be agnostic about whether the world is or is not really Modular). Someone may justify this claim that it is Modular insofar as our best knowledge comes from a working hypothesis of Modularity that is a heuristic guiding synthetic biology research.
} 
theses of M/modularity apply, and the referent to which they apply (e.g. processes, objects, relationships, and properties).

\subsection{Assembly Methods Affecting Modularity}

Synthetic biology is based on a general thesis of biological Modularity (Knight 2003; Morange 2009a). The parts database of biological modules with wellcharacterized functions relies on this working hypothesis and the success of synthetically produced networks and parts in practice seems to bear this out at least in some limited capacity. Taking a practice-focused approach to understanding Modularity suggests that the assembly method one uses affects the nature of Modularity of the parts, devices, and pathways one constructs.

The most commonly used assembly method, BioBrick assembly, is based on the standardization of basic parts with a prefix and a suffix (Knight 2003). Addition of these two short DNA sequences to any DNA element results in a BioBrick. Two BioBricks can be ligated together in either order to construct a composite that is itself a BioBrick containing a prefix and a suffix (Kendig and Eckdahl 2017). The central concept that enables BioBrick assembly to work is that type II restriction enzymes XbaI and SpeI produce compatible sticky ends (Kendig and Eckdahl 2017). BioBrick assembly has been a popular method from its inception. However, it is not without problems. BioBrick assembly depends on purification of DNA fragments after gel electrophoresis. The pairing of the DNA recognition sequences for $\mathrm{XbaI}$ and SpeI during ligation results in a mixed site that practitioners refer to as a BioBrick scar (Brent 2004; Endy 2005). The scar is six DNA nucleotides in length and has a defined sequence. There are applications in which the spacing between two parts must be smaller than six nucleotides or when the BioBrick scar sequence confounds the function of a device (Kendig and Eckdahl 2017). Another problem with BioBrick assembly is that once ligated together, two BioBricks cannot be taken apart for use in another construct (Knight 2003). Assembled BioBricks are components that can no longer be swappable or interchangeable. In this way, the generation of the scar during BioBrick assembly affects the kinds of parts produced and their degree of Modularity. Being Modular means something different during BioBrick assembly because of this known outcome. ${ }^{6}$

\subsection{Modularity and Modularizing}

The claim of modularity is a claim specific to the compositional structure that parts and wholes exemplify in a particular system. As such, modularity is an answer to questions concerning: What is the nature of parts in that particular device or

${ }^{6}$ An extended discussion of modularity based on this example is contained in Kendig and Eckdahl (2017). 
pathway?, How are they organized?, or What is the relationship of the compositional structure of them to the whole in question? It characterizes the property and nature of modulehood. This second kind of modularity avoids the problems that befall Modularity regarding different assembly methods. The things that are categorized as modular are numerous and may come about due to differing processes of assembly or categorization. This kind of modularity defines modules by the action of modularizing. The assembly method used makes parts into modules insofar as they are chosen by practitioners to be connected or separated from other parts. What counts as a module (variously understood) and the criteria for modular kindhood may not be the same for all modules. That is, modularity may not be a property that can be univocally expressed for all parts-modularity allows for this.

This kind of modularity is not without problems. To say something is a module or part has typically meant that it bears some sameness relationship, family resemblance, or overlapping shared homeostatic set of properties to another part qua module. In this way, being a module - insofar as it is understood to be a propertymeans that it is a property that is instantiable in one way. This means that all modules insofar as they are modules are homogeneously so. I think this is a mistake. This modulehood may be a kind differently instantiated. That is, modulehood for one thing may not be the same as modulehood for another in a radical and noncomparative way. Some might suggest that this brings into question the legitimacy of what it is that we refer to when we claim something is a module if there is no unifying claim. When faced with this proposition, they may prefer to dispense with all claims of modularity and become eliminitivists. Alternatively, they may embrace the heterogeneity of modulehood and allow that modulehood may be radically heterogeneous across all metaphysically parcelled out stuff. Despite its initial simple understanding, all modules may not belong to the same sui generis categorymodularity may not be something that is univocally expressed.

\section{Evolvability}

I move now from mapping out some of the conceptual terrain of modularity within synthetic biology to that of evolvability. How can evolvability be characterized in synthetic biology ${ }^{7}$ ? I suggest that it may be best understood as the capacity of a population, organism, device, part, or pathway to change over time - that evolvability is the facilitated variation of self-organized systems (cf. Calcott 2014). Conceived in this way it can serve as an umbrella term under which natural, artificial, and synthetic change over time can be covered.

Evolvability relies on phenotypes being both plastic and stable. Phenotypes of organisms are plastic insofar as they are responsive to the continual variation within their environment. Phenotypes of organisms are stable insofar as they may develop

\footnotetext{
${ }^{7}$ For a recent discussion of evolvability and synthetic engineering that is complementary to the one presented here, see Calcott (2014).
} 
reliably despite changes in the resources available to the organisms. Novel phenotypes arise through the rearranging or recombining of ancestral phenotypes by the organism (West-Eberhard 2005: 6543). Organisms are able to coordinate the resources used in their own development because they are:

richly endowed with a capacity for facilitating variation, a small input of random mutation would lead to a large output of viable phenotypic variation ... Instead of a brittle system, where every genetic change is either lethal or produces a rare improvement in fitness, we have a system where many genetic changes are tolerated with small phenotypic consequences and whereas others may have selective advantages, but are also tolerated because physiological adaptability suppresses lethality (Kirschner and Gerhart 2005: 226).

If facilitated variation is the mechanism of natural selection, then it would appear that the inputs are modules. Organismal modularity maintains robustness of pathways whilst allowing recombination of relatively autonomous entities. Facilitated variation can be understood as explaining the evolvability of organisms through its self-organizing processes and its relationships to genetic and extragenetic resources. In this sense, the evolvability of organisms may be underpinned by the specific modularity thesis that takes the nature of organisms to be organized modularly. Organisms may change their features depending on a number of factors. These changes can be attributable to the self-organizing capacities of organisms in selecting which resources, in what order, and in what combination, are used as causes of their own development. The organism could be understood to be the author of its own variability. Its generic capacities may constrain deleterious variation or enhance variability that may be advantageous to it. Using these capacities, organisms may either buffer or enhance any variations to their genetic or extragenetic resources or perturbations in their inter- or extra-cellular environmental resources (Kendig 2014a).

An organism has both constraints and de-constraints on the variability of its phenotype. Its capacity for variation allows it to maintain itself across a wide range of conditions. The organism's potential for different developmental variations lie in its capacity to self-organize its genetic and extragenetic resources. The organism's common stock of generic capacities and resources has been understood by Mary Jane West-Eberhard (2003: 146) as its "phenotypic repertoire". The organism's phenotypic repertoire includes a number of highly conserved core processes: intercellular signalling and cell sorting (Goodwin et al. 1993); the capacity for weak linkage, exploratory behaviour, spatial patterning, compartmentation and modularity of the body plan (cf. Kirschner and Gerhart 2005); the capacity of tissues to segment or form hollow tubes (cf. Minelli 2003); and the capacity to learn and remember (West-Eberhard 2003: Ch. 3, 7, 18). A thumbnail sketch of some of the ways in which variation is facilitated may be useful.

The capacity for weak linkage allows organisms to use a small number of mechanisms relying mostly on the ability to reconfigure these as and when necessary for different functions. But because these linkages are weak, they are often retraced and duplicated by other pathways or circuits to strengthen them. The use of weak linkages means that there is higher versatility which the organism can use to alter these pathways when necessary. They offer a socket and plug model that facilitates interchangeability of different modules. If these were strong, static and unchanging 
linkages, the organism would be arguably less fit to adjust to different environmental situations (Kirschner and Gerhart 2005: 136-7). In the course of evolution small changes result in wide variability and novelty. Weak linkages can be formed in many kinds of interactions, such as those between cells, cell populations, tissues, organs, organ systems, and behaviours. In this way, they confer a standardized way of connecting different modules to one another. Because these linkages are weak, individual organs, cells, tissues, or behaviours may also change independently. The exploratory behaviour of organisms is their responsiveness to different inputs and outputs. In building such things as neural networks or circuits, the organism begins by constructing a large number of alternative pathways. The best of these alternative pathways are selected and stabilized.

A conserved body plan - one that is retained over a succession of individual organisms - enables independent variation of some features without adversely affecting others. It does so by compartmentation of the body plan into semiautonomous functional and structural parts. This modularity of the organism's parts increases its capacity for variation as changes in one subunit do not greatly affect others and thereby reduces the possibility of lethal variations. The more modular these subunits become, the greater the possibility of variation and specialization of these structural and functional units within the organism. The generic capacity to learn through exploratory behaviour provided certain motivating factors, such as the absence or presence of certain resources needed in the construction of a particular phenotypic trait or the performance of certain processes or behaviours (e.g. metabolism, reproduction, locomotion, speech), enables the organism to vary its phenotype over its lifetime in a range of different contexts. Organisms may learn about their resources and environment by quorum sensing, by chemical cues or by virtue of their sensory organs. They may manipulate the objects within their immediate habitat, investigate new resources or interact with new organisms (e.g. prey, potential mates, carers, symbionts) within this habitat, or search for a new one. Certain types of activities associated with access to food, protection from weather, increased sociality or reproductivity, or fitness may result in some benefit or detriment to the organism). Activities that effectively increase or substantially decrease resources are remembered and repeated or avoided. These generic capacities allow organisms to vary their own development and the phenotypes they construct depending on how resources are used (Kendig 2014a).

\subsection{How Can Engineered Metabolic Pathways Be Maintained?}

Building on the discussion of facilitated variation in the last section, I now use this to return to discuss it in light of particular examples of metabolic engineering in microbial organisms to explain how pathways can be maintained in synthetic biology. Metabolic engineering depends on the discovery and investigation of natural metabolic pathways and the genetic elements that control them, on using that information to transform suitable host organisms for the desired orthogonal metabolism, and on 
optimization of the metabolic output. The most high-profile product of metabolic engineering resulted in bacteria and yeast cells that produce the anti-malarial drug artemisinin, reducing its cost of production compared to purification from the sweet wormwood plant (Martin et al. 2003). Another is the recent attempts to engineer cells to make more of what they may make already, (e.g., single-celled algae producing oil, or producing a variation on what they would normally produce). This is exemplified in the current research trend in publically and privately funded projects is to investigate the potential use of various species of algae for biofuel production (Kendig 2014b). Algae produce lipids (oil) as a byproduct of the process of photosynthesis. The hope is that once the means of harnessing this store of energy is found, algal biofuels may provide an inexpensive alternative source of fuel that can be produced with little more than sunlight, carbon dioxide, and a small amount of water. While advances in synthetic biology research and the understanding of algal alternatives increase, the scaling up of these fuels requires significant further research resolving the problems of system optimization and photosynthetic efficiency as well as solving ways of producing these synthetic biofuels in quantities suitable for commercial use (Georgianna and Mayfield 2012). Various species of bacteria and yeast have been considered as particularly suitable for research into the production of synthetic biofuels (Dellomonaco et al. 2010). Cyanobacteria are another that initially appears promising. Cyanobacteria, like Synechocystis sp. PCC 6803, can provide a highly efficient organic system for producing biofuels as they can convert solar energy and carbon dioxide into biofuel molecules (Wang et al. 2013). Cyanobacteria are particularly good candidates because they possess naturally occurring biosynthetic pathways that produce alkanes (a key component of gasoline, diesel, and jet fuel). At present, research into the use of cyanobacteria for synthetic biofuel production is still in the very early stages and well behind that of algae research. However, research focused on reconfiguring these to create an organism that produces alkanes or alkenes at a rate that is double that of the wild type has been shown to be possible. Synechocystis mutants have been constructed that overexpress alkane biosynthetic genes (Kendig 2014b). If their photosynthetic pathways were re-engineered, cyanobacteria may be able to produce alkanes or alkenes at a highly efficient rate (Wang et al. 2013).

But knowing how to sustain the orthogonal pathway over generations requires resolution of two problems. I refer to the first of these as the optimization problem. The optimization problem involves figuring out how synthetic biologists can enhance orthogonal metabolic output when they cannot know all of the variables that affect it in a host organism and its environment. I call the second problem the natural selection problem. How can the reduction in fitness in a population of organisms engineered for an orthogonal metabolic pathway be prevented from causing evolution away from the desired metabolic output phenotype? The native metabolism of all organisms is responsive to a vast array of internal and external variables including genotype, metabolite availability, $\mathrm{pH}$, osmotic pressure, and temperature (Eckdahl et al. 2015). ${ }^{8}$ When synthetic biologists introduce orthogonal metabolism

${ }^{8}$ For an extended discussion of this example see Kendig and Eckdahl (2017) and Eckdahl et al. (2015). 
into a host organism, they can optimize metabolic output by taking into account the variables they know, but must ignore all of the variables they don't know and some that they cannot know. Synthetic biology researchers also struggle with the difficulty of trying to make sure that the organisms they engineer with the ability to carry out orthogonal metabolism continue to faithfully replicate that genetic capacity. If the production of the product or the maintenance of the pathway is too onerous for the cell, the metabolic pathway will (after a number of generations) be disposed of. Those organisms without the onerously produced product or taxing pathway will be selected for in preference to those constructed to function by the synthetic biologist. To sum up in one sentence: synthetic biology's biggest obstacle is natural selection.

\subsection{Is Semisynthetic Evolvability Still Evolvability?}

In the previous section, I suggested that evolvability may be understood as the capacity of an organism, device, part, or pathway to change over time- that evolvability is the facilitated variation of self-organized systems. Conceived of in this way, evolvability was able to be used as an umbrella concept under which natural, artificial, and synthetic change over time can be covered. I now want to question the legitimacy of this as a category or kind. I suggest that synthetic biological research, as well as the orthogonal products and processes that it creates, sits in a liminal position between engineered technological kinds (cf. Schyfter 2012) and natural (or in the language of synthetic biology "native") biological kinds. If this liminality exists, it presents difficulties with regard to the notion of kindhood if kindhood is understood to be a property of the contents of the world as already there for us. Why? To explain, I'll use the butchery metaphor often used to explain the nature of natural kinds as being understood as picking out the natural categories in the world as carving nature at its joints. Synthetic biological research and the orthogonal products and processes that arise from it would suggest a notion of kindhood that does not rely on the pre-carved up contents of the world but instead a notion that involves the role of the carvers and-following the discussion of how assembly methods may affect modularity - the ascription of the joints.

As such, the goal of understanding evolvability is directed to the potential to modify and optimize the modules, networks and systems which direct it. This takes evolvability to be a capacity that can be defined, represented, measured, intervened upon and optimized. We might do better to call this "semisynthetic evolvability" as it differs from natural or artificial evolvability in that the synthetic biology practitioner actively intervenes in the process of facilitated variation and employs the use of a suite of constructed parts and employs populations of organisms to solve the biological problem of optimization.

But the question remains: are semisynthetic evolvability and the umbrella concept of evolvability as facilitated variation of self-organized systems legitimate and veridical categories of evolvability? And how are we to judge them? According to Morange, "Selection in nature and evolution directed by biochemists and molecular 
biologists increasingly differ as technological progress is made in synthetic biology" (Morange 2009a: 370). At first blush, this would suggest that semisynthetic evolvability may not count as evolution at all. Later on, however, Morange provides an alternative account. He argues against his initial suggestion that synthetically tweaked evolution does not count as evolution. He goes on to argue that current understanding of evolution is based on an unwarranted assumption of univocalism that could be challenged by findings in synthetic biology:

some of the extraordinary scenarios of evolution, designed by synthetic biologists, must be carefully considered by evolutionary biologists. Maybe the models provided by evolutionary biologists are too restrictive, leaving too much place to uniformitarianism, the hypothesis that the mechanisms of evolution have always remained the same (Morange 2009a: 374).

Put stronger, perhaps evolutionary biologists have just been getting it wrong. Natural evolvability is actually more like semisynthetic evolvability. So research into the latter may yield understanding of the former. Judged according to Morange's second suggestion, the umbrella category of evolvability can also be viewed as veridical insofar as it captures the heterogeneity of synthetic, artificial, and natural evolutionary mechanisms as well as their concomitant epistemic categories.

\section{The Social Aspect of Scientific Investigation}

In the foregoing, I have attempted to show that attending to the practices within synthetic biology - in particular to the reengineering of metabolic pathwaysreveals the generation of knowledge-making categories and the delineation of modules within the manipulation of biological parts, processes, and systems. I now turn to the social aspect of the practitioners' work. Although the specific focus on metabolic engineering is new, doing so relies heavily on Marjorie Grene's much earlier identification of the work of scientists as being not just the subject of epistemology but also of ethical engagement. Writing in 1966, Grene states that scientists' "work" is "an instance of the recognition of responsible persons, a performance of the same general kind as the recognition of patterns, individuals, or persons" (Grene 1966: 223). Grene refers to the social nature of science as work that takes place in "social enterprises" (Grene 1985). But Grene is not alone in pointing to the ineliminability of the social within scientific inquiry. It has been characterized more recently in terms of "systems of practice" (Chang 2012), referred to in virtue ethics as "agentbased" interactions (Swanton 2003), been described as "social cognition" (Longino 1990), and in some sense, it has been much earlier cashed out in terms of the concept of "conviviality" (Polanyi 1962). I build on this formindable work, focusing on the social aspect of scientific investigation and the notion of a system of practice in order to identify the work of practitioners in a reticulated set of knowledge-making activities.

Following Grene, I take the work of scientists to rely on protocols as sets of explicit and implicit rules of action. The action of individual agents within the social 
group of scientists is not the work of idealized decision-makers but seems to be biased on individuals whose beliefs are not entirely self-generated. That is, they do not form in a vacuum but from within a particular context and environment. As such, scientists working within social enterprises are agents that act from a particular embedded standpoint. Grene's view seems underpinned by an agent-based view that investigates a perspective where action is always from a standpoint, but that the standpoint is located in social networks of knowledge producing practices. It is that place from which and as such a precondition for personal action. In this way Grene appears to rely on Polanyi's notion of agency (see Polanyi 1962, and in particular, see Mullins 2009 for a discussion of Polanyi's notion of agency). For Polanyi, science is only considered possible within a society that acknowledges it by affirming the sorts of questions, types of reasoning, and value of their pursuit, advancement, and transmission of knowledge. Polanyi (1962: 203) suggests that scientific knowledge is only possible because the sharing of knowledge is itself valued in society. That it is valued, makes science possible. He suggests that reliance on this social endorsement is pervasive - it is prerequisite to all epistemic and ethical knowledge. Polanyi illustrates the pervasiveness:

I cannot speak of a scientific fact, of a word, of a poem or a boxing champion; of last week's murder or the Queen of England; of money or music or the fashion in hats, of what is just or unjust, trivial, amusing, boring or scandalous, without implying a reference to a consensus by which these matters are acknowledged — or denied to be-what I declare them to be. I must continually endorse the existing consensus or dissent from it to some degree, and in either case I express what I believe the consensus ought to be in respect to whatever I speak of (Polanyi 1962: 209).

More recently, the pervasiveness of the social aspect of scientific enquiry as prerequisite for objective knowledge is later explored by Longino (1990). Longino's interest is in characterizing the nature of knowledge acquisition, but she cautions,

Because we think the goal of the scientist's practice is knowledge, it is tempting to follow tradition and seek solutions in abstract or universal rules. Refocussing on science as practice makes possible the second shift, which involves regarding scientific method as something practiced not primarily by individuals but by social groups (Longino 1990: 66).

The social nature of scientific practice that Longino suggests here emphasizes the intimate connection between the character of inquiry as a social and is prerequisite for what she refers to as "social cognition"- the idea that scientific inquiry is not simply an individual pursuit but an epistemic activity relying on the intersubjectivity of critical dialogue within scientific study. In doing so, she follows Grene $(1966,1985)$ in fleshing out the nature of what it means to be a social enterprise and what I suggest Chang (2012) later identifies as a system of practice. According to Chang, the search for an agent-free or context-free set of categories is simply one that is ill-founded in philosophy. This is because knowledge is always something bound within what he refers to as a "system of practice":

A system of practice is formed by a coherent set of epistemic activities performed with a view to achieve certain aims...[A]s with coherence of each activity, it is the overall aims of a system of practice that define what it means for the system to be coherent. The coherence 
of a system goes beyond mere consistency between the propositions involved in its activities: rather, coherence consists in various activities coming together in an effective way toward the achievement of the aims of the system (Chang 2012: 16).

By focusing on systems of practice, Chang foregrounds the activities and goals of scientists within the pursuit of knowledge rather than with the product of their activity - the observations statements and their truth value. It is not the veridicality of statements on their own that tells us what constitutes success in science. In order to understand truth or anything like it, it is necessary to investigate how these statements function within the knowledge-making activities of scientists. The assessing of truth or truthlikeness of any statement is valuable but context dependent (Chang 2012: 17-18). Truth can only be assessed within the constraints of the goals and by the values set out by practitioners that are for instance, working towards solving a particular problem. That is, what counts as a solution depends on what is determined to be the problem.

What appears to connect Grene's notion of social enterprises, Longino's social cognition, and Chang's systems of practice is a sense of the pervasiveness of the social nature of scientific investigation-a pervasiveness highlighted by Polanyi's notion of conviviality, social endorsement, and dissent. I explore the pervasiveness of the social by looking once again to Polanyi's notions in order to characterize an account of ethics. According to Polanyi, it is not the agreement of the community of individuals that leads to knowledge but the possibility of disagreement (Polanyi 1962). Being in a community provides the environment that makes disagreement possible. To disagree is to see oneself as being against something and in the possibility of communicating that disagreement to another. Applying a Polanyi-inspired approach to normative ethics, I suggest that normative ethical evaluations are the result of loops of ethical reflectiveness of agents in a multi-agent network of practitioners who construct the grounds for ethical knowledge through their intersubjective judgements. That is, normative ethical evaluations rely on what people think, what they do, how they do it, and how they communicate it to others. These evaluations are dependent on the epistemic capabilities of individuals multiply instantiated in networks of practitioners. In synthetic biology, these networks include human agents, but also their physical manipulations (e.g. measuring, weighing, running gels), mathematical modelling, proxied or remote tool use, objects of study (e.g. chassis organisms, BioBricks), and the extended social communities that they work within (e.g. research networks that span multiple institutions, iGEM competitions, international research networks). They are spatially, socially, and temporally extended.

\subsection{Extended Agency Ethics}

In the remaining, I briefly consider how synthetic biology practice reveals valuational as well as the epistemic and ontological categories of research. I suggest that ethical categories, like the knowledge-making practices, are formed alongside these 
within socially extended research groups and sketch an approach to understanding the generation of ethical knowledge. I refer to this form of ethical knowledge as "extended agency ethics" to emphasize the intersubjective nature of this social approach. Extended agency ethics can be understood as taking a naturalistic agentbased approach to ethics. I clarify the descriptors "extended" and "agency" one at a time before bringing them together. I refer to this approach as "extended" because this view relies on the extended-mind thesis in cognitive science (Clark 1995; Clark and Chalmers 1998). According to the extended mind thesis, thinking is not exclusively something that happens in the brain, it is something that is spatiotemporally extended (Clark and Chalmers 1998; Clark 2010). Mind includes brain but also includes tools used to aid thinking (e.g. language, culture, pencils, calculators, search engines, mobile phone apps, and other people). Knowledge is not just epistemologically embedded according to this view, but it shapes and is reciprocally shaped by our experiences in the world:

we use intelligence to structure our environment so that we can succeed with less intelligence...it is the human brain plus these chunks of external scaffolding that finally constitutes the smart, rational inference engine that we call mind (Clark 1998: 180).

I use this extended mind thesis to suggest how ethical decision making is ineliminably connected to the research practiced in groups-but these are groups of individuals capable of acting. I refer to "agency" in the description of the approach to indicate that the role of the individual agent. This agent based view of action implies that we, as agents, are the locus of our activities, e.g. measuring, mapping, or running gels, in order to effect changes beyond merely measuring, mapping, or running gels. Agents act for and towards a purpose beyond those movements. They are able to do so because they have certain causal knowledge of the result of the performance of these actions. ${ }^{9}$ The agents' activities are not reducible to the events of measuring, mapping, or running gels because it is the person's running a gel and not the gel'sto assume that these are the same thing is to reduce the agency of the agent to an event. Keeping in mind the ubiquity of the social as expressed by Polanyi, Grene, Longino, and Chang, extended agency ethics does not assume that intentionality is the sole domain of the individual nor that the decisions of the individual are autonomous. Individual scientists' work is generated through a social process and forms a kind of interactive extended agency. That is, their research activities are extended over the members of the research group and coordinated in virtue of their shared intentionality in the form of extended cognition. These shared intentions provide the grounds for normativity in scientists' social research interactions. Robert Wilson has recently suggested a view of extended agency akin to the one I have developed here and elsewhere, (Kendig 2016a), but within a separate context. ${ }^{10}$ He provides a

${ }^{9}$ I follow Hornsby's account of irreducible agent causation here, (see Hornsby 2004: 11-14 for further discussion of agency in philosophy of action and Lowe 2009: 196-201 for further distinction between agent causation and event causation).

${ }^{10}$ Wilson's (2018) discussion of normativity is given in the context of the eugenics movement and in particular, within a critical analysis of the cognitive processes that lead to the marking of certain human variation as deficient and other variation as preferred within scientific practice. 
particularly helpful way of understanding how sociocognitive intentions can be construed as being the basis for normativity:

Normativity exists when there is a distinction between a correct, proper, or appropriate way for a process, event, or outcome to turn out, and an incorrect, improper or inappropriate such way. Like extended cognition, normativity arises in and through both non-human and human cognition; it is not solely a feature of our own species' activity. [L]ike extended cognition, the most familiar and robust forms of normativity are those that are the product of distinctly human practices and institutions that presuppose a kind of shared intentionality...So we have a kind of externally mediated, cognitively driven normativity, and it constitutes an important feature of human social life (Wilson 2018: 130).

Agency is, therefore, not restricted to the individual or to a limited number of individuals. It can extend to the social research network one participates within with its requisite values and practices. Extended agency provides a conception of the social character of scientific inquiry that attempts to make sense of it as research that is extended across events, environments, objects, and agents. My suggestion is that responsibility for the form of ethical evaluations is therefore also distributed across the system of agents within the network of practitioners.

So, what would a normative ethical decision-making process look like using extended agency ethics? In pursuing research to find a suitable organism to be used as a chassis for biofuel production, a team of researchers would use knowledge acquired from the related areas of research outputs of projects focusing on cyanobacteria, algae, and metabolism. They may use this broad investigative approach to narrow down the range of possible candidates for a chassis organism. They may initially investigate the current algae research and the metabolic pathway of the highly familiar, well-researched green algae, Chlamydomonas reinhardtii. Knowledge of the successes and problems associated with the reengineering of algae as a source of biofuel may lead to the choice of a cyanobacteria instead. Once a chassis is selected, they may focus attention on the synthetic construction of pathways that overexpress alkane biosynthetic genes. Following this, they may begin the task of generating stocks of the newly reengineered form of Synechocystic sp. In order to plan the most efficient scale-up ventures, economists as well as microbiologists may be contracted. Once enough product is produced, they may outsource some beta tests to chemical engineers for kinematic viscosity analysis of the cyanobacteria-based biofuel product. They may request assistance in testing combustibility from colleagues specializing in physical chemistry. Limitations on what can be known and what can be done may come from the reciprocal knowledge exchanged through these interactions as well as with the cultures and communities potentially affected by the production of products. The normative ethical decisions and projectable outcomes are obtained through and by these interactions. Knowledge of the organism being used, the marketability of the product, the scale of production, and the social and environmental impacts are all linked to the particular organism used. That is, the ethical evaluations of biofuel production varies depending on the organism used, the scaling applied, the prospects for environmental controls, expected social effects, communication of these, and the impact on local and world economics. 
Extended agency ethics describes the integrated approach to ethical decisionmaking as one that requires careful and critical consideration of integrated research and technological activities in order to reasonably predict possible outcomes. Ethical decisions concerning the potential use of Synechocystic- based biofuel is not something that comes as purely either backward looking assessment or forward speculation. The determination of what should be done is not something that can be judged solely on the basis of weighing up consequences of action, nor on the basis of rule- following - categorical or otherwise. Instead, ethical considerations-such as the permissibility of the development of some new technology (e.g. cyanobacterial- based biofuels) - are determined according to the current research, the experiential data amassed, the practitioners' knowledge-making activities, and the potential for scaling up production of the biofuel products by industry. This means that the locus of normative agency and intentionality is distributed across the activities of research groups, tools, and the development of products.

In this way, extended agency provides an externalist view of justification. Justification for beliefs come not from the decision-making-inside-the-head version of internalism (as some set of brain-bounded intuitionism or reflective perception). Instead, a form of active externalism that distributes cognition socially and agency across spatiotemporal research practices is suggested to explain the nature of scientific inquiry and the acquisition of knowledge. The ability to form research questions and pursue this kind of research depends on the aims of the system of practitioners within a particular research environment. As such, extended agency radically revises the conditions under which beliefs are considered to be justified. Justification can be on the basis of reflection on decision making as a form of mental cognition, but according to extended agency, what is taken to be mental cognition is not restricted to the brain but instead goes beyond the skull and can extend to tools, practices, processes, and other researchers and social research groups-social cognition. Both epistemic credit and ethical culpability are distributed notions that extend beyond the individual human agent. If social cognition, the social aspect of scientific practice, and the extended mind thesis are taken seriously, mental states (usually restricted to the brain by internalist evidentialists) are extended not only beyond the brain and skin of the individual but to include other spatiotemporally distinct biological, technological, and socially extended entities. With this extended cognition, a requisite extended agency and normative ethics based on this actively externalist theory of evidence follows. In some meaningful sense, extended agency can be understood to be a kind of role-based approach to ethics that demarcates categories of valuation analogous to those epistemic categories (outlined in the first half of this chapter). That is, to act in a role is to act according to a category of activity or to follow a model or prototypic way of acting. It may be profitably understood as being akin to an Aristotelian notion of virtue or a context- driven valuation. The intimacy of epistemic and ethical knowing is explicitly articulated by a number of virtue ethicists (see in particular Swanton's 2003: 249 "virtues as prototypes"). Instead of understanding morality as being based on a set of rules, this approach takes virtues to be frameworks. These frameworks are built from interactions and in-practice experience that both shapes and is shaped by future interactions in the 
world (Swanton 2003: 279). Christine Swanton's "virtues as prototypes" can be seen as a more restricted version of my extended agency ethics. Whereas Swanton limits knowledge of the world to agent-based interactions, I extend it further to include agent-object based interactions. That is, I include interactions between humans, but also between humans and their objects, technological artefacts, and tools of investigation.

I hope my extension will help to build a bridge between philosophy of science and sociology of science. The bridge can be understood in terms of a shared locus of research: the study of interactions and associations between social actors. The interactions between social actors - whether they be technological artefact, machine, or human-consist of a system of valuing within these systems of scientific practices. The normative status of the interactions, objects, and human actors comes from the valuing of practitioners, the scientific methods they choose, activities that they participate in, the tools and measuring devices that they select in their field of study to use, and the meaning attached to the information gained from those tools. These all constitute sources of meaning within the use and interaction with them in various ways. The aim of the extended agency approach outlined here has been to begin to explain agent-object based interactions within scientific research groups. In the next section, I suggest that these object-human interactions can be best understood through a combined sociology and philosophy of science.

\subsection{Bridging Philosophy of Science and Sociology of Science}

In his pivotal paper, "Mixing humans and nonhumans together: the sociology of a door-closer", Bruno Latour, (writing under the pseudonym "Jim Johnson"), suggests that studying the interaction between humans, machines, and tools should be the remit of a more widely extended approach to the study of sociology of science. He argues that if things we commonly refer to as a tool or a machine affect the way we interact in the world, then they might also be considered social actors. Considering them as such would blur the line that is often drawn between what is "purely technical" and what is "purely social" (Latour 1988: 198). He shows by means of a series of examples, (e.g. a hydraulic door closer and a red stop light), that some technological objects prescribe the behaviours of humans who interact with these artefacts. He focuses in particular on tools and technological objects that stand in for humans or take on the work of humans, (e.g. the hydraulic door opener that takes on the job of a human groom who opens the door for us, or a traffic light that takes on the job of a police officer who signals that we should stop in traffic). Although they are not human, the hydraulic door opener and the traffic light determine the norms of behaviour considered appropriate when we encounter them and sets the normative terms of interaction. That is, we interact with the non-human door-closer and the traffic light in terms of the roles each occupies. Knowing the role these technological objects play means that we also know what actions we should take in response to them. They bring with them the norms for how to interact with them. That these 
technological artefacts might be informed by our interaction with a polite human opening a door for us or a police officer who directs traffic in an area where no traffic lights exist does not seem to count against the normative interaction present when we drive up to a light and act according to certain norms. That the light is not a person doesn't mean we fail to understand that we should stop when it changes to red. The object in some sense normatively frames our experiences with it. It interacts with us in terms of how it interprets our role in the interaction. Latour calls the normativity that arises from the machine's presuppositions about the role of the human user, "prescriptivism".

Prescriptivism is whatever a scene presupposes from its transcribed ${ }^{11}$ actors and authors (this is very much like 'role expectation' in sociology, except that it may be inscribed or encoded in the machine). For instance, a Renaissance Italian painting is designed to be viewed from a specific angle of view prescribed by the vanishing lines, exactly like a traffic light expects that its users will watch it from the street and not sideways. In the same way as they presuppose a user, traffic lights presuppose that there is someone who has regulated the lights so that they have a regular rhythm (Latour 1988: 306).

Latour suggests we consider interactions with scientific objects and technological artefacts (and not just people) to be social interactions. As such, he argues that sociology should treat the material or technological objects we relate to as not just of peripheral social interest but of direct sociological significance. Doing so requires what Andrew Pickering calls "a decentering of the social relative to the material and the conceptual, in terms of both objects of analysis and explanatory formats" (Pickering 2005: 352). The current chapter attempts to follow Pickering's approach to decentered sociology by "exemplifying empirically and theoretically what a decentered sociology can look like, in the hopes of encouraging others to follow" (Pickering 2005: 353). In the above, I have attempted to provide a case study of how the tools and assembly methods chosen by synthetic biology practitioners may be themselves a sociological topic as well as a philosophical topic. They affect the process of knowledge production as well as the normative judgements of practitioners about the products produced within the collaborative social practice of research itself. Sociological investigation of the material and conceptual tools that affect knowledge production within labs may sheds light on how tools and decisions about tool use within systems of practitioners are made. In this way, normative as well as epistemic aspects of scientific research seem to require an understanding of social relations and not just a philosophical explanation of knowledge production. A decentered social theory and a decentered philosophical theory that focus on the role of technological objects may provide the best account of the normative interactions within collaborative groups of scientists.

\footnotetext{
${ }^{11}$ Latour uses "transcription" and "inscription" to explain the transition from a less durable delegated agent to perform an action to a more reliable one. For instance, "the replacement of a policeman by a traffic-light" is an instance where the traffic light is delegated the work that was done by a police officer. In Latour (1988), the focus is on descriptions of meaning that these actors play within a particular semiotic script. How actors are defined and what is meant by their roles in a particular scenario.
} 


\section{Concluding Remarks}

The account of both epistemological and ethical ineliminability of scientific practice developed here aims to provide non-reductive grounding to knowledge in social cognition and within social enterprises. The possibility of critical dissent by the individual practitioner against the protocols, types of reasoning, modes of knowledge transmission, or generation of research questions affirmed by the community is what is required for knowledge. That requires the role of the practitioner as individual agent to be something that is irreducible to the social group or system of practice itself. Rather than a relationship of reduction of the individual to the social, the individual practitioner as agent can been understood to be working towards the goal of scientific knowledge and the performance of it using diverse methods. The practitioner extends her knowledge by making connections with other practitioners, making use of protocols endorsed by the community, using reliable model organisms to make her hypotheses, critically responding to accepted routes of knowledge generation, and networking her resources together in the performance of scientific inquiries. As an agent, she brings these resources together and in turn becomes a resource within the system of practice that she works within.

Investigating a practice-based route of acquiring knowledge within synthetic biology presents an alternative way of exploring traditional metaphysical questions in philosophy such as: What are the kinds of things synthetic biology produces? What is the relationship between parts and wholes? It also introduces new questions about what it is to be a part or indeed the property of partness itself within a new field; questions not just of interest to metaphysicians of science. Instead of seeking to understand the use of epistemological and ontological categories in practice from the premise that their existence can be known a priori or contained within the theoretical framework of the discipline that uses them, this approach runs in the opposite direction. It instead suggests that categories come into being in practice and from these categories-in-use theoretical concepts, notions of causal directionality, functional architectures, and normative valuation arise through the active engagement of systems of practitioners.

Acknowledgements Research for this chapter was partially funded by the National Science Foundation Division of Molecular and Cellular Biosciences (MCB), BIOMAPS: Modular Programmed Evolution of Bacteria for Optimization of Metabolic Pathways, Grant No. MCB1329350, Amendment No. 001, Proposal No. MCB-1417799. Thanks to Todd Eckdahl, Jeff Poet, Malcolm Campbell, and Laurie Heyer for sharing their insights and expertise in synthetic biology with me during research for the project. Special thanks go to Phil Mullins for many lively discussions about Polanyi and for encouragement in the early stages of writing this chapter. I am also very grateful to Hauke Riesch, Brian Rappert, and Thomas Reydon for their feedback on earlier versions of the manuscript. 


\section{References}

Brent, R. 2004. A Partnership Between Biology and Engineering. Nature Biotechnology 22: 1211-1214.

Calcott, B. 2014. Engineering and Evolvability. Biology and Philosophy 29 (3): 293-313.

Chang, H. 2004. Inventing Temperature: Measurement and Scientific Progress. New York: Oxford University Press.

- 2011. How Historical Experiments Can Improve Scientific Knowledge and Science Education: The Cases of Boiling Water and Electrochemistry. Science \& Education 20: $317-341$.

2012. Is water H2O? New York: Springer.
2014. Units of Analysis in Philosophy of Science After the Practice Turn. In Science After the Practice Turn in the Philosophy, History, and Social Studies of Science, ed. L. Soler, S. Zwart, M. Lynch, and V. Israel-Jost. London: Routledge.

Chang, H. 2016. The rising of chemical natural kinds through epistemic iteration. In Natural kinds and classification in scientific practice, ed. C. Kendig, 33-46. Abingdon/ New York: Routledge.

Clark, A. 1995. I Am John's Brain. Journal of Consciousness Studies 2 (2): 144-148.

- 2010. Supersizing the Mind: Embodiment, Action, and Cognitive Extension. Oxford: Oxford University Press.

- 1998. Being there: Putting brain, body, and world together again. Cambridge: MIT Press. Clark, A., and D. Chalmers. 1998. The Extended Mind. Analysis 58: 7-19.

Dellomonaco, D., F. Fava, and R. Gonzolez. 2010. The Path to Next Generation Biofuels: Successes and Challenges in the Era of Synthetic Biology. Microbial Cell Factories 9: 3. https://doi. org/10.1186/1475-2859-9-3.

De Regt, H., S. Leonelli, and K. Eigner, eds. 2009. Scientific Understanding: A Philosophical Perspective. Pittsburgh: University of Pittsburgh Press.

Dupré, J. 1993. The Disorder of Things: Metaphysical Foundations of the Disunity of Science. Cambridge, MA: Harvard University Press.

. 2006. Humans and Other Animals. Oxford: Clarendon Press.

Eckdahl, T.T., A.M. Campbell, L.J. Heyer, J.L. Poet, D.N. Blauch, N.L. Snyder, et al. 2015. Programmed Evolution for Optimization of Orthogonal Metabolic Output in Bacteria. PLoS One 10 (2): e0118322. https://doi.org/10.1371/journal.pone.0118322.

Endy, D. 2005. Foundations for Engineering Biology. Nature 438 (24): 449-453.

Erwin, D., and E. Davidson. 2009. The Evolution of Hierarchical Gene Regulatory Networks. Nature Reviews Genetics 10: 141-148.

Georgianna, R., and S. Mayfield. 2012. Exploiting Diversity and Synthetic Biology for the Production of Algal Biofuels. Nature 488: 329-335.

Gibson, D., J. Glass, C. Lartigue, V. Noskov, R.-Y. Chuang, M. Algire, et al. 2010. Creation of a Bacterial Cell Controlled by a Chemically Synthesized Genome. Science 329 (5987): 52-56.

Goodwin, B., S. Kauffman, and J. Murray. 1993. Is Morphogenesis an Intrinsically Robust Process? Journal of Theoretical Biology 163: 35-144.

Grene, M. 1966. The Knower and the Known. Berkeley: University of California Press. 1985. Perception, Interpretation, and the Sciences: Toward a New Philosophy of Science. In Evolution at a Crossroads, ed. D.J. Depew and B.H. Weber, 1-20. Cambridge, MA: MIT Press.

Hacking, I. 1992. The Self-Vindication of the Laboratory Sciences. In Science as Practice and Culture, ed. A. Pickering, 29-64. Chicago: University of Chicago Press.

- 1995. The Looping Effects of Human Kinds. In Causal Cognition: A Multidisciplinary Debate, ed. D. Sperber, D. Premack, and A.J. Premack, 351-394. New York: Clarendon Press. Hornsby, J. 2004. Agency and Actions. In Agency and Action, ed. J. Hyman and H. Steward, 1-23. Cambridge: Cambridge University Press.

Hylton, W. 2012. Craig Venter's bugs might save the world. The New York Times, March 6. 
Keller, E.F. 2009. Knowledge as Making, Making as Knowing: The Many Lives of Synthetic Biology. Biological Theory 4 (4): 333-339.

Kendig, C. 2014a. Towards a Multidimensional Metaconception of Species. Ratio 27 (2): 155-172.

- 2014b. Synthetic Biology and Biofuels. In Encyclopedia of Food and Agricultural Ethics, ed. P.B. Thompson and D.M. Kaplan, 1695-1703. New York: Springer.

- 2016a. What Is Proof of Concept Research and How Does It Generate Epistemic and Ethical Categories for Future Scientific Practice? Science and Engineering Ethics 22 (3): 735753. https://doi.org/10.1007/s11948-015-9654-0.

- 2016b. Activities of kinding in scientific practice. In Natural kinds and classification in scientific practice, ed. C. Kendig, 1-13. Abingdon/New York: Routledge.

—., ed. 2016c. Natural Kinds and Classification in Scientific Practice. Abingdon/New York: Routledge.

Kendig, C., and T.T. Eckdahl. 2017. Reengineering metaphysics: Modularity, parthood, and evolvability in metabolic engineering. Special issue: Ontologies of living beings (eds A.M. Ferner and Thomas Pradeu) Philosophy, Theory, and Practice in Biology 9(8). https://doi.org/10.3998/ ptb.6959004.0009.008.

Kirschner, M., and J. Gerhart. 2005. The Plausibility of Life. New Haven: Yale University Press.

Knight, T. 2003. Idempotent Vector Design for Standard Assembly of Biobricks. MIT Synthetic Biology Working Group.

Latour, B./Johnson, J. 1988. Mixing Humans and Nonhumans Together: The Sociology of a DoorCloser. Social Problems 35 (3): 298-310.

Longino, H. 1990. Science as Social Knowledge: Values and Objectivity in Scientific Inquiry. Princeton: Princeton University Press.

Lowe, E.J. 2009. A Survey of Metaphysics. Oxford: Oxford University Press.

Martin, V.J., D.J. Pitera, S.T. Withers, J.D. Newman, and J.D. Keasling. 2003. Engineering a Mevalonate Pathway in Escherichia coli for Production of Terpenoids. Nature Biotechnology 21 (7): 796-802.

Minelli, A. 2003. The development of animal form. Cambridge: Cambridge University Press.

Morange, M. 2009a. Synthetic Biology: A Bridge Between Functional and Evolutionary Biology. Biological Theory 4 (4): 368-377.

- 2009b. A Critical Perspective on Synthetic Biology. HYLE 15 (1): 21-30.

Mullins, P. 2009. Polanyi on Agency and Some Links to MacMurray. Appraisal 7 (3): 11.

O’Malley, M. 2009. Making Knowledge in Synthetic Biology: Design Meets Kludge. Biological Theory 4 (4): 378-389.

O’Malley, M., A. Powell, J. Davies, and J. Calvert. 2008. Knowledge-Making Distinctions in Synthetic Biology. BioEssays 30: 57-65.

Pickering, A. 2005. Decentering Sociology: Synthetic Dyes and Social Theory. Perspectives on Science 13 (3): 352-405.

Polanyi, M. 1962. Personal Knowledge: Towards a Post-critical Philosophy. Chicago: University of Chicago Press.

Rheinberger, H.-J. 2005. A Reply to David Bloor: Toward a Sociology of Epistemic Things. Perspectives on Science 13: 406-410.

Rouse, J. 1996. Engaging Science: How to Understand Its Practices Philosophically. Ithaca/ London: Cornell University Press. 2003. How Scientific Practices Matter. Chicago: University of Chicago Press.

Schlosser, G., and G. Wagner, eds. 2004. Modularity in Development and Evolution. Chicago: University of Chicago Press.

Schyfter, P. 2012. Technological Biology? Things and Kinds in Synthetic Biology. Biology and Philosophy 27: 29-48.

Soler, L., ed. 2012. Characterizing the Robustness of Science: After the Practice Turn in Philosophy of Science. Volume 292 Boston Studies in the Philosophy of Science. New York: Springer.

Soler, L., S. Zwart, M. Lynch, and V. Israel-Jost, eds. 2014. Science After the Practice Turn in the Philosophy, History, and Social Studies of Science. London: Routledge. 
Sprinzak, D., and M. Elowitz. 2005. Reconstruction of Genetic Circuits. Nature 438 (7067): 443-448.

Swanton, C. 2003. Virtue Ethics: A Pluralistic View. Oxford: Oxford University Press.

Wagner, G., M. Pavlicev, and J. Cheverud. 2007. The Road to Modularity. Nature Reviews Genetics 8: 921-931.

Wang, W., X. Liu, and X. Lu. 2013. Engineering Cyanobacteria to Improve Photosynthetic Production of Alka(e)nes. Biotechnology for Biofuels 6: 69. http://www.biotechnologyforbiofuels.com/content/6/1/69. Accessed 1 Nov 2015.

West-Eberhard, M. 2003. Developmental Plasticity and Evolution. Oxford: Oxford University Press.

2005. Developmental plasticity and the origin of species differences. PNAS 102: 6543-6549.

Wilson, R. 2018. The Eugenic Mind Project, 99-140. Cambridge/London: MIT Press. 
Hauke Riesch • Nathan Emmerich

Steven Wainwright

Editors

\section{Philosophies and Sociologies of Bioethics}

Crossing the divides

睹 Springer 
Editors

Hauke Riesch

Department of Sociology

and Communications

Brunel University

London, UK

Steven Wainwright

Department of Social \& Political Sciences

Brunel University London

Uxbridge, Middlesex, UK
Nathan Emmerich

ANU Medical School

Australian National University

Canberra, Australia

The Institute of Ethics,

Dublin City University

Dublin, Ireland

School of History, Anthropology,

Politics and Philosophy

Queen's University Belfast

Belfast, UK

ISBN 978-3-319-92737-4 ISBN 978-3-319-92738-1 (eBook)

https://doi.org/10.1007/978-3-319-92738-1

Library of Congress Control Number: 2018948009

(C) Springer International Publishing AG, part of Springer Nature 2018

This work is subject to copyright. All rights are reserved by the Publisher, whether the whole or part of the material is concerned, specifically the rights of translation, reprinting, reuse of illustrations, recitation, broadcasting, reproduction on microfilms or in any other physical way, and transmission or information storage and retrieval, electronic adaptation, computer software, or by similar or dissimilar methodology now known or hereafter developed.

The use of general descriptive names, registered names, trademarks, service marks, etc. in this publication does not imply, even in the absence of a specific statement, that such names are exempt from the relevant protective laws and regulations and therefore free for general use.

The publisher, the authors and the editors are safe to assume that the advice and information in this book are believed to be true and accurate at the date of publication. Neither the publisher nor the authors or the editors give a warranty, express or implied, with respect to the material contained herein or for any errors or omissions that may have been made. The publisher remains neutral with regard to jurisdictional claims in published maps and institutional affiliations.

Printed on acid-free paper

This Springer imprint is published by the registered company Springer International Publishing AG part of Springer Nature.

The registered company address is: Gewerbestrasse 11, 6330 Cham, Switzerland 